\title{
PREPARATIVE SEPARATION OF ISOQUINOLINE ALKALOIDS FROM PHELLODENDRI CORTEX BY PH-ZONE-REFINING COUNTER-CURRENT CHROMATOGRAPHY
}

\author{
Daijie Wang ${ }^{\mathrm{b}}$, Shanming Tian ${ }^{\mathrm{a}, *}$, Li Cui ${ }^{\mathrm{b}}$, Huijiao Yan ${ }^{\mathrm{b}}$, Xiangyun Song ${ }^{\mathrm{b}}$, Yuguo Liu ${ }^{\mathrm{a}}$, Fei Xu and Junjian Ma $^{\mathrm{b}}$ \\ aShandong Cancer Hospital Affiliated to Shandong University, Jinan 250117, China \\ ${ }^{\mathrm{b}}$ Shandong Analysis and Test Center, Key Laboratory of TCM Quality Control, Jinan 250014, China
}

Recebido em 12/09/2017; aceito em 07/11/2017; publicado na web em 18/01/2018

\begin{abstract}
pH-Zone-refining counter-current chromatography (PZRCCC) was successfully used for preparative separation isoquinoline alkaloids from Phellodendri Cortex. Two target compounds of berberine and palmatine were completely resolved by a two-phase solvent system chloroform/methanol/water $(4: 2: 2, v / v)$, with $10 \mathrm{mmol} \mathrm{L}^{-1} \mathrm{HCl}$ in upper stationary phase and $10 \mathrm{mmol} \mathrm{L}^{-1} \mathrm{TEA}$ in lower organic phase. From $2.0 \mathrm{~g}$ of the crude alkaloids, palmatine $(448 \mathrm{mg}, 95.1 \%)$ and berberine $(159 \mathrm{mg}, 95.4 \%)$ were obtained in one-step PZRCCC separation. The chemical structures were identified by ESI-MS and NMR data. The results indicated that PZRCCC separation is an excellent preparative separation method for isoquinoline alkaloids from Phellodendri Cortex.
\end{abstract}

Keywords: Phellodendri Cortex; isoquinoline alkaloids; palmatine; berberine; pH-Zone-Refining Counter-Current Chromatography.

\section{INTRODUCTION}

Phellodendri Cortex, known as "Guan Huang Bai" in Chinese, is a well-known oriental folk medicine of China. It is obtained from the dried trunk bark of Phellodendron amurense Rupr. and widely spread in North and Northeast of China. Phellodendri Cortex has been widely used as a common anti-inflammatory drug in various diseases, such as protecting neurodegenerative human brain diseases, inflammatory induced by 12-O-tetradecanoylphorbol-acetate, human osteoarthritic cartilage and chondrocytes. ${ }^{1-4}$ Recent studies revealed that Phellodendri Cortex had potential effects on anti-diarrhea, infectious pulmonary disease, neuroprotective effect, inhibiting prostatic contractility and tumor cell proliferation. . $^{5-10}$

The major chemical constituents of Phellodendri Cortex are isoquinoline alkaloids, such as palmatine and berberine. The two compounds are used as the phytochemical marker for the quality control of Phellodendri Cortex in Chinese Pharmacopoeia. ${ }^{11}$ Besides the function of anti-inflammatory, berberine has the functions of hepatoprotection, improving cognitive impairment, treating atherosclerosis, protecting against neurotoxicity, anti-diabetic nephropathy effect. ${ }^{12-20}$ Palmatine also has broad biological activities, such as hepatoprotective effect, anti-breast cancer, chondroprotective and cardioprotective effect, etc. $^{21-25}$

Previously, isoquinoline alkaloids from Phellodendri Cortex were isolated and purified by conventional techniques, such as polyamide chromatography, sephadex LH-20, SI and silica gel column chromatography, which were a waste of organic solvent, tedious, time-consuming. ${ }^{26-29}$ Thus, effective separation methods for isoquinoline alkaloids from Phellodendri Cortex are of great importance.

High-speed counter-current chromatography (HSCCC) has now been widely applied in the separation of various compounds, as a liquid-liquid partition chromatography. As a special separation mode of HSCCC, pH-zone-refining counter-current chromatography (PZRCCC), which was introduced as a large-scale preparative chromatography, has been successfully applied for the largescale separation of organic acids and alkaloids. ${ }^{30-34}$ PZRCCC is characteristic of higher sample loading capacity, higher concentration

*e-mail: t.mingming@163.com and purity of the collected fractions, and higher enrichment efficiency of minor compounds.

The present paper describes the successful separation isoquinoline alkaloids from Phellodendri Cortex by PZRCCC, as well as the optimized of some critical parameters of PZRCCC. The chemical structures were elucidated by ESI-MS and NMR spectroscopic analyses (shown in Figure 1).

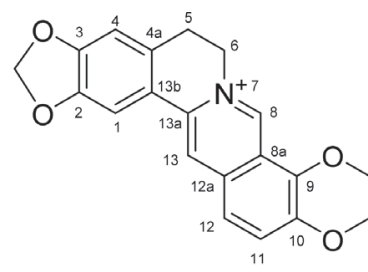

Berberine

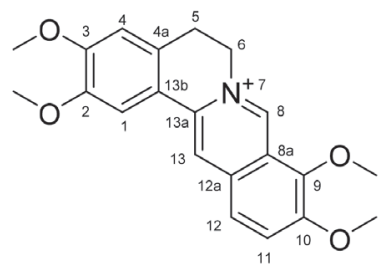

Palmatine
Figure 1. Structures of the compounds from Phellodendri Cortex

\section{EXPERIMENTAL}

\section{Apparatus}

The HSCCC separation was carried out on a TBE-300A (Tauto Biotechnique, Shanghai, China), which was equipped with a $300 \mathrm{~mL}$ PTFE multilayer coil (diameter of the PTFE tube as $1.6 \mathrm{~mm}$ ) as well as a $20 \mathrm{~mL}$ manual sample loop. The rotation speed of the column coil could be adjustable from 0 to $1000 \mathrm{rpm}$. The HSCCC apparatus was also equipped with four other instrument modules, including a TBP-5002 constant-flow pump (Tauto Biotechnique, Shanghai, China), a 8823A-UV Monitor at $254 \mathrm{~nm}$ (Beijing Emilion Technology, Beijing, China), a Model 3057 portable recorder (Yokogawa, Sichuan Instrument Factory, Sichuan, China) and a DC-0506 low constant temperature bath (Tauto Biotechnique, Shanghai, China) to maintain the temperature at $25^{\circ} \mathrm{C}$.

A Waters e2695 equipment with a 2695 quaternary-solvent delivery system, a 2996 Photodiode Array Detection (DAD) detector, an automatic sample injection, a 2695 column oven and an Empower 3 ChemStation was used to analyze the crude extract and the collected fractions. The column used was a Waters Symmetry $\mathrm{C}_{18}$ column (250 mm $\times 4.6 \mathrm{~mm}$, i.d. $5 \mu \mathrm{m}$, Waters, Milford, MA, USA). 


\section{Materials}

Ethanol, petroleum ether $\left(60-90^{\circ} \mathrm{C}\right), n$-hexane, ethyl acetate, methanol, ammonia solution, chloroform, $\mathrm{HCl}$, triethylamine (TEA) and ammonium chloride were analytical grade (Sinopharm Chemical Reagent Co., Ltd, Shanghai, China). Acetonitrile used in HPLC analysis were of HPLC grade (Fisher Scientific, Fair Lawn, NJ, USA). The water used was deionized by an osmosis Milli-Q system (Millipore, Bedford, MA, USA).

Phellodendri Cortex, the dried trunk bark of Phellodendron amurense Rupr., was obtained from Jian-lian TCM store and identified by Dr Li Jia (College of Pharmacy, Shandong University of Traditional Chinese Medicine, China).

\section{Sample preparation}

Phellodendri Cortex (500 g) was grounded and sieved to 40-60 mesh. The powder was extracted with a reflexing method by $70 \%$ ethanol ( 3 times, $2 \mathrm{~h}$ each time). The extraction solution was filtrated, combined and removed the ethanol by reduced pressure distillation $\left(40^{\circ} \mathrm{C}\right)$. Then, the left of sample water solution was extracted with equal volume petroleum ether 3 times and adjusted to $\mathrm{pH} 9$ with dilute ammonia solution.

The alkaline sample aqueous solution was extracted with equal volume 3 times. After chloroform removed by reduced pressure distillation $\left(40{ }^{\circ} \mathrm{C}\right), 21 \mathrm{~g}$ total alkaloids from Phellodendri Cortex was obtained for further isolation and purification.

\section{Preparation of solvent systems and sample solutions}

A two phase solvent system composed of chloroform/methanol/ water $(4: 2: 2, v / v)$ was set in a separating funnel. After shocked sufficiently, the two solvent systems were divided into two phases for further experiment. The upper phase was adjusted to $10 \mathrm{mmol} \mathrm{L}^{-1} \mathrm{HCl}$ (stationary phase). The lower phase was as mobile with $10 \mathrm{mmol} \mathrm{L}^{-1}$ TEA. $2.0 \mathrm{~g}$ of the total alkaloids from Phellodendri Cortex was dissolved in $10 \mathrm{~mL}$ of acidified upper phase and $10 \mathrm{~mL}$ of without alkaline lower phase.

\section{PZRCCC separation}

The multiplayer coiled column was full of the upper phase at 30.0 $\mathrm{mL} / \mathrm{min}$, and then sample solutions were injected into the sample port. The instrument was set at $850 \mathrm{rpm}$ and the mobile phase was pumped into the column at $2.0 \mathrm{~mL} / \mathrm{min}$. Fractions were collected manually every five minutes with monitor at $254 \mathrm{~nm}$. After the separation finished, the solvent in the column was blowout with an air compressor. The retention of the stationary phase was defined as the upper volume divided by the total volume.

\section{Analysis and identification of PZRCCC peak fractions}

The total alkaloids from Phellodendri Cortex and each collected fractions of PZRCCC were analyzed by HPLC with a Waters Symmetry $\mathrm{C}_{18}$ column $(250 \mathrm{~mm} \times 4.6 \mathrm{~mm}$, i.d. $5 \mu \mathrm{m})$. The mobile phases were composed of acetonitrile (A) and $0.4 \mathrm{M}$ ammonium chloride solution (B). Gradient elution mode was set as follows: 0-25 min for 5-43\% A, 25-50 min for $43-90 \%$ A. The detection wavelength was monitored at $254 \mathrm{~nm}$. The injection volume and flow-rate were set at $10 \mu \mathrm{m}$ and $1.0 \mathrm{~mL} / \mathrm{min}$.

The identification of HSCCC peak fractions were performed by ESI-MS experiments on an Agilent 6520 Q-TOF (Agilent, Santa Clara, CA, USA) and NMR spectra were performed on a Bruker
AV-400 spectrometer (Bruker BioSpin, Rheinstetten, Germany) with TMS as an internal standard.

\section{RESULTS AND DISCUSSION}

\section{Optimization of HPLC condition}

In reversed phase HPLC, the $\mathrm{pH}$ value and composition of mobile phase are the crucial factor in alkaloids analysis. Alkaloids with different $\mathrm{pKa}$ values are influenced by the $\mathrm{pH}$ value of the solution. If the $\mathrm{pH}$ value is out of $\mathrm{pKa} \pm 2$, the retention time is stabilized. ${ }^{35,36}$ In the process of optimization HPLC condition, a series of solvent system was optimized, including acetonitrile/20 $\mathrm{mmol} \mathrm{L}^{-1}$ phosphoric acid solution $(\mathrm{pH}=2.1)$, acetonitrile $/ 50 \mathrm{mmol} \mathrm{L}^{-1}$ potassium dihydrogen phosphate solution $(\mathrm{pH}=4.6)$ and acetonitrile $/ 50 \mathrm{mmol} \mathrm{L}^{-1}$ ammonium chloride solution $(\mathrm{pH}=5.3)$. When acetonitrile $/ 50 \mathrm{mmol} \mathrm{L}^{-1}$ ammonium chloride solution was used as the basic solution, a good separation could be obtained. When gradient elution mode was set as 0-25 min for 5-43\% A, 25-50 min for 43-90\% A, the retention time and peak shape were proper.

\section{Optimization of PZRCCC conditions}

The isoquinoline alkaloids in Phellodendri Cortex are quaternary ammonium type and the most polar type of alkaloids. These kinds of alkaloid are soluble both in acid and base state. In the solvent system selection of PZRCCC, two series systems including $n$-Hex-EtOAc-MeOH- $\mathrm{H}_{2} \mathrm{O}$ and $\mathrm{CHCl}_{3}-\mathrm{MeOH}-\mathrm{H}_{2} \mathrm{O}$ were used. When the two solvent system $n$-Hex-EtOAc-MeOH- ${ }_{2} \mathrm{O}$ (5:5:2:8, $v / v)$ was used, the $K_{\mathrm{D}}$-values in acid and base state were less than 0.05 (Table 1). This means berberine and palmatine could be eluted immediately with no peak resolution. In consideration of the $K_{\mathrm{D}}$-values of $\mathrm{CHCl}_{3}-\mathrm{MeOH}-\mathrm{H}_{2} \mathrm{O}(4: 3: 2, v / v)$ and $(4: 2: 2, v / v)$, the PZRCCC separation mode was carried out.

Table 1. The $K_{\mathrm{D}}$-values of target compounds in different solvent

\begin{tabular}{|c|c|c|c|}
\hline Solvent system & & $K_{1}$ & $K_{2}$ \\
\hline \multirow{2}{*}{ n-Hex-EtOAc-MeOH- $\mathrm{H}_{2} \mathrm{O}(5: 5: 2: 8, \mathrm{v} / \mathrm{v})$} & $K_{\text {acid }}$ & $<0.05$ & $<0.05$ \\
\hline & $K_{\text {base }}$ & $<0.05$ & $<0.05$ \\
\hline \multirow{2}{*}{$\mathrm{CHCl}_{3}-\mathrm{MeOH}-\mathrm{H}_{2} \mathrm{O}(4: 3: 2, \mathrm{v} / \mathrm{v})$} & $K_{\text {acid }}$ & 2.24 & 1.60 \\
\hline & $K_{\text {base }}$ & 0.09 & 0.07 \\
\hline \multirow{2}{*}{$\mathrm{CHCl}_{3}-\mathrm{MeOH}-\mathrm{H}_{2} \mathrm{O}(4: 2: 2, \mathrm{v} / \mathrm{v})$} & $K_{\text {acid }}$ & 3.43 & 2.33 \\
\hline & $K_{\text {base }}$ & $<0.05$ & $<0.05$ \\
\hline
\end{tabular}

Figure 2A showed the PZRCCC separation of $2.0 \mathrm{~g}$ crude alkaloids with the solvent system of $\mathrm{CHCl}_{3}-\mathrm{MeOH}-\mathrm{H}_{2} \mathrm{O}(4: 3: 2, v / v)$ with $10 \mathrm{mmol} / \mathrm{L} \mathrm{HCl}$ in upper phase and $10 \mathrm{mmol} \mathrm{L}^{-1} \mathrm{TEA}$ in lower phase. The $K_{\mathrm{D}}$-values of palmatine and berberine in acid state were 2.24 and 1.60 , while the $K_{\mathrm{D}}$-values in base state were 0.09 and 0.07 . However, palmatine and berberine were not fully separated. The retention of stationary was $53 \%$. When the solvent system changed to $\mathrm{CHCl}_{3}-\mathrm{MeOH}-\mathrm{H}_{2} \mathrm{O}(4: 2: 2, v / v)$ with $10 \mathrm{mmol} / \mathrm{L} \mathrm{HCl}$ in upper phase and $10 \mathrm{mmol} \mathrm{L}^{-1} \mathrm{TEA}$ in lower phase, the $K_{\mathrm{D}}$-values of palmatine and berberine in acid state increased to 3.43 and 2.33. And the $K_{\mathrm{D}}$-values in base state were less than 0.05 . When the sample size was $2.0 \mathrm{~g}$ as shown in Figure 2B, the retention of stationary was $50 \%$, and the two compounds were fully separated. $448 \mathrm{mg}$ of Palmatine and $159 \mathrm{mg}$ of berberine were obtained in one-step separation, with the purities of $95.1 \%$ and $95.4 \%$ as determined by HPLC, respectively (Figure 2B and 2C). 


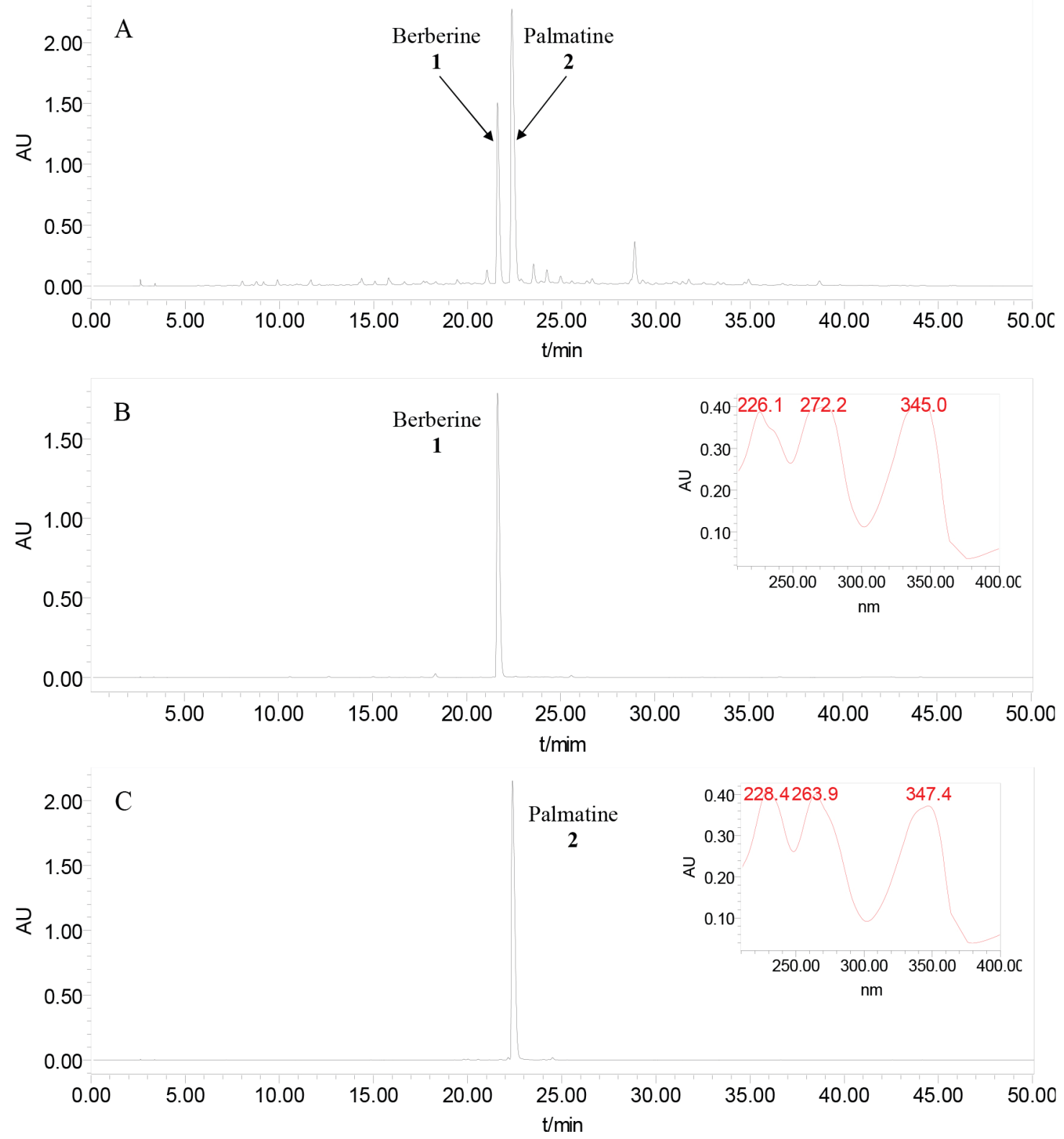

Figure 2. (A) HPLC chromatograms of the crude alkaloids from Phellodendri Cortex; (B) HPLC analysis and UV spectrum of the berberine ( 2 in Figure $3 B$ ) purified with PZRCCC; (C) HPLC analysis and UV spectrum of the palmatine (1 in Figure 3B) purified with PZRCCC. Experimental conditions: Waters Symmetry $C_{18}$ column $(250 \mathrm{~mm} \times 4.6 \mathrm{~mm}$, i.d., $5 \mu \mathrm{m})$; Mobile phase: acetonitrile (A)/0.4 mol L-1 ammonium chloride solution (B), gradient elution mode: 0-25 min for 5-43\% A, 25-50 min for 43-90\% A. Flow rate: $1.0 \mathrm{~mL} / \mathrm{min}$; Detection: $254 \mathrm{~nm}$; Injection volume: $10 \mu \mathrm{L}$

\section{The structural identification}

The chemical structures of alkaloids from Phellodendri Cortex were identified by comparison of their spectroscopic data reported, including ESI-MS and NMR data.

Berberine $^{37}$ (1, peak II in Figure 3): ESI-MS, m/z $337[\mathrm{M}+\mathrm{H}]^{+}$. ${ }^{1} \mathrm{H}-\mathrm{NMR}\left(400 \mathrm{MHz}, \mathrm{DMSO}-d_{6}\right) \delta$ : 9.88 (1H, s, H-8), 8.94 (1, s, H-13), $8.21(1 \mathrm{H}, \mathrm{d}, J=9.2 \mathrm{~Hz}, \mathrm{H}-12), 8.01(1 \mathrm{H}, \mathrm{d}, J=9.2 \mathrm{~Hz}, \mathrm{H}-11), 7.80(1 \mathrm{H}$, s, H-1), 7.09 (1H, s, H-4), 6.18 (2H, s, O- $\left.\mathrm{CH}_{2}-\mathrm{O}\right), 4.93(2 \mathrm{H}, \mathrm{t}, J=6.2$ $\mathrm{Hz}, \mathrm{H}-6), 4.07,4.10\left(3 \mathrm{H}\right.$, each, s, $\left.2 \times \mathrm{OCH}_{3}\right), 3.21(2 \mathrm{H}, \mathrm{t}, J=6.2 \mathrm{~Hz}$, H-5). ${ }^{13} \mathrm{C}-\mathrm{NMR}\left(100 \mathrm{MHz}, \mathrm{DMSO}-d_{6}\right) \delta: 150.3$ (C-10), $149.9(\mathrm{C}-3)$, 147.7 (C-2), 145.5 (C-8), 143.6 (C-9), 137.5 (C-13a), 132.9 (C-12a), 130.6 (C-4a), 126.8 (C-11), 123.8 (C-12), 121.4 (C-8a), 120.5 (C-13), 120.2 (C-13b), 108.5 (C-4), 105.4 (C-1), 102.0 (-O-CH$\left.{ }_{2}-\mathrm{O}-\right), 61.9$ $\left(9-\mathrm{OCH}_{3}\right), 55.9\left(10-\mathrm{OCH}_{3}\right), 55.2(\mathrm{C}-6), 26.3(\mathrm{C}-5)$.

Palmatine $^{38}$ (2, peak I in Figure 3): ESI-MS, $m / z 353[\mathrm{M}+\mathrm{H}]^{+}$.
${ }^{1} \mathrm{H}-\mathrm{NMR}\left(400 \mathrm{MHz}, \mathrm{DMSO}-d_{6}\right) \delta: 9.86(1 \mathrm{H}, \mathrm{s}, \mathrm{H}-8), 9.04(1 \mathrm{H}, \mathrm{s}$, $\mathrm{H}-13), 8.17$ (1H, d, J=9.2 Hz, H-11), $8.02(1 \mathrm{H}, \mathrm{d}, J=9.2 \mathrm{~Hz}, \mathrm{H}-12)$, 7.69 (1H, s, H-1), 7.07 (1H, s, H-4), 4.93 (2H, t, $J=6.4 \mathrm{~Hz}, \mathrm{H}-6)$, 4.08, 4.05, 3.92, $3.85\left(3 \mathrm{H}\right.$, each, s, $\left.4 \times \mathrm{OCH}_{3}\right), 3.21(2 \mathrm{H}, \mathrm{t}, J=6.4 \mathrm{~Hz}$, $\mathrm{H}-5) .{ }^{13} \mathrm{C}-\mathrm{NMR}$ (100MHz, DMSO- $\left.d_{6}\right) \delta$ : 152.4 (C-9), 150.1 (C-3), 149.8 (C-2), 145.8 (C-8), 143.8 (C-10), 138.4 (C-13a), 134.5 (C-4a), 129.1 (C-12a), 127.3 (C-12), 123.9 (C-11), 122.0 (C-13b), 120.8 (C-13), 118. 8 (C-8a), 112.4 (C-4), 108.9 (C-1), 62.1 (C-9OMe), 57.6 (C-3OMe), 56.8 (C-10OMe), 56.3 (C-2OMe), 56.1 (C-6), 27.0 (C-5).

\section{CONCLUSION}

In the present study, an efficient PZRCCC separation was used to preparative separate isoquinoline alkaloids from Phellodendri Cortex. In PZRCCC separation, a two-phase solvent system chloroform/ methanol/water $(4: 2: 2, v / v)$ was used, with $10 \mathrm{mmol} \mathrm{L}^{-1} \mathrm{HCl}$ in 

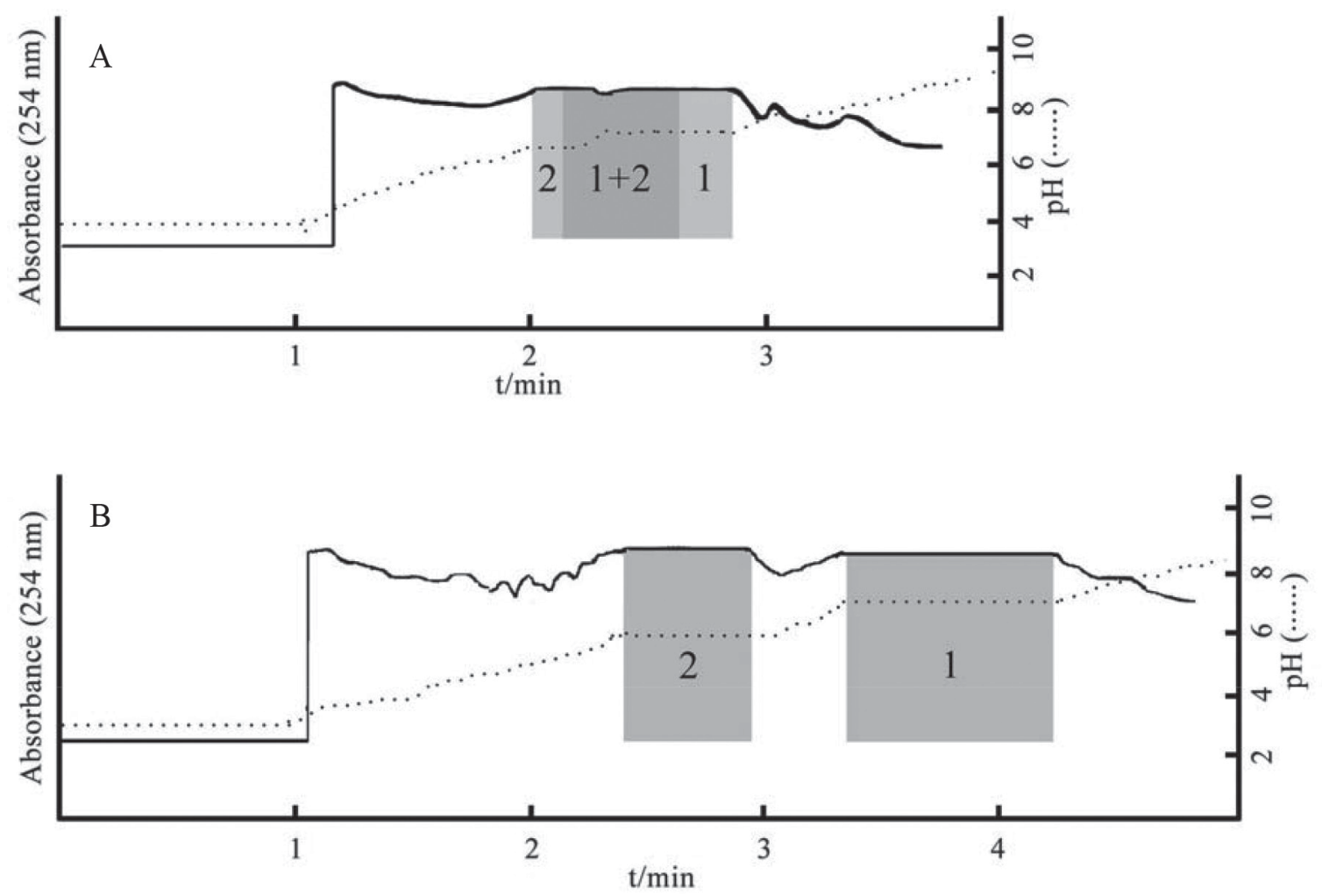

Figure 3. PZRCCC Chromatogram of the crude extract. (A) chloroform/methanol/water $(4: 3: 2, \mathrm{v} / \mathrm{v}), 10 \mathrm{mmol} \mathrm{L}^{-1} \mathrm{HCl}$ in stationary phase and $10 \mathrm{mmol} \mathrm{L}^{-1}$ TEA in mobile phase, retention of stationary phase: $44.6 \%$; (B) chloroform/methanol/water $(4: 2: 2, v / v), 10 \mathrm{mM} \mathrm{HCl}$ in stationary phase and $10 \mathrm{mmol} \mathrm{L}^{-1} \mathrm{TEA}$ in mobile phase, retention of stationary phase: 50.0\%; Experimental mode: head-to-tail; Mobile phase: the lower phase; Separation Flow rate: $2.0 \mathrm{~mL}$ min ${ }^{-1}$; Revolution speed: $850 \mathrm{rpm}$; Detection wavelength: $254 \mathrm{~nm}$; Sample size: $2.0 \mathrm{~g}$; Injection volume: $20 \mathrm{~mL}$; 1: palmatine; 2: berberine

upper stationary phase and $10 \mathrm{mmol} \mathrm{L}^{-1} \mathrm{TEA}$ in lower organic phase. Two compounds of palmatine and berberine with high purities were obtained in one-step PZRCCC separation. As isoquinoline alkaloids are quaternary ammonium type and easily soluble in water and chloroform. Traditional solvent system of $n$-Hex-EtOAc-MeOH- $\mathrm{H}_{2} \mathrm{O}$ is not fit to separate the polar type of alkaloids. In series of solvent of chloroform/methanol/water, the $K_{\mathrm{D}}$-values in acid and base state are the crucial factor. If the $K_{\mathrm{D}}$-values are smaller in base state and bigger in acid base state, a good separation effect can be obtained. The present method proved to be efficient to separate isoquinoline alkaloids with high polarity. This developed methodology could be applied to rapidly separate preparative pure compounds in further research from Phellodendri Cortex and its alkaloids. It also could be used to obtain compounds for biological studies.

\section{ACKNOWLEDGEMENTS}

Financial support from the Science Foundation of China (21506119), Shandong Province Major Scientific and Technological Innovation Project (2017CXGC1308), Primary Research \& Developement Plan of Shandong Province (Grant No. 2017GSF216002) and the Three-academy Joint Funds of Shandong Provincial Natural Science Foundation (ZR2016YL006) are gratefully acknowledged.

\section{REFERENCES}

1. Kim, J.; Huh, J.; Baek, Y.; Lee, J.; Choi, D.; Park, D.; J. Ethnopharmacol. 2011, 134, 234.

2. Choi, Y. Y.; Kim, M. H.; Han, J. M.; Hong, J.; Lee, T.; Kim, S.; Yang, W. M.; Int. Immunopharmacol. 2014, 19, 214.
3. Xian, Y.; Mao, Q.; Ip, S.; Lin, Z.; Che, C.; J. Ethnopharmacol. 2011, $137,1425$.

4. Park, Y.; Chung, Y. S.; Kim, Y. S.; Kwon, O.; Joh, T. H.; Int. Immunopharmacol. 2007, 7, 955.

5. Tsai, J.; Tsai, S.; Chang, W.; J. Ethnopharmacol. 2004, 93, 21.

6. Xu, Y.; Ventura, S.; J. Ethnopharmacol. 2010, 127, 196.

7. Yan, H.; Sun, X.; Sun, S.; Wang, S.; Zhang, J.; Wang, R.; An, P.; Yang, F.; Kang, W.; Int. J. Biol. Macromol. 2011, 48, 720.

8. Xian, Y.; Lin, Z.; Ip, S.; Su, Z.; Chen, J.; Lai; X.; Phytomedicine 2013, 20, 187.

9. Garcia, G. E.; Nicole, A.; Bhaskaran, S.; Gupta, A.; Kyprianou, N.; Kumar, A. P.; Neoplasia 2006, 8, 523.

10. Mao, Y.; Li, Y.; Zong, L.; You, X.; Lin, F.; Jiang, L.; Immunopharmacol. Immunotoxicol. 2010, 32, 110.

11. Editorial Committee of the Pharmacopoeia of People's Republic of China, The Pharmacopoeia of People's Republic of China (Part I), Beijing, China Medical Science and Technology Press 1999, 146.

12. Lin, Y.; Sheng, M.; Weng, Y.; Xu, R.; Lu, N.; Du, H.; Yu, W.; Biochem. Biophys. Res. Commun. 2017, 483, 885.

13. Huang, M.; Jiang, X.; Liang, Y.; Liu, Q.; Chen, S.; Guo, Y.; Exp. Gerontol. 2017, 91, 25.

14. Feng, M.; Zou, Z.; Zhou, X.; Hu, Y.; Ma, H.; Xiao, Y.; Li, X.; Ye, X.; Int. Immunopharmacol. 2017, 43, 195.

15. Zhang, C.; Li, C.; Chen, S.; Li, Z.; Jia, X.; Wang, K.; Bao, J.; Liang, Y.; Wang, X.; Chen, M.; Li, P.; Su, H.; Wan, J.; Lee, S.; Liu, K.; He, C.; Redox Biol. 2017, 11, 1.

16. Jin, Y.; Liu, S.; Ma, Q.; Xiao, D.; Chen, L.; Eur. J. Pharmacol. 2017, 794, 106

17. Allijn, I. E.; Czarny, B. M.S.; Wang, X.; Chong, S. Y.; Weiler, M.; Silva, A.; Metselaar, J. M.; Lam, C.; Pastorin, G.; Kleijn, D.; Storm, G.; Wang, J.; Schiffelers, R. M.; J. Controlled Release 2017, 247, 127. 
18. Ma, W.; Zhu, M.; Zhang, D.; Yang, L.; Yang, T.; Li, X.; Zhang, Y.; Phytomedicine 2017, 25, 45.

19. Lin, W.; Lin, J.; Int. Immunopharmacol. 2011, 11, 1984.

20. Mitani, N.; Murakami, K.; Yamaura, T.; Ikeda, T.; Saiki, I.; Cancer Lett. 2001, 165, 35 .

21. Yan, B.; Wang, D.; Dong, S.; Cheng, Z.; Na, L.; Sang, M.; Yang, H.; Yang, Z.; Zhang, S.; Yan, Z.; Int. Immunopharmacol. 2017, 45, 194.

22. Lee, W.; Kim, J.; Kang, J.; Oh, W.; Jung, J.; Kim, Y. S.; Jung, H. A.; Choi, J. S.; Lee, S.; Food Chem. Toxicol. 2010, 48, 222.

23. Wu, J.; Xiao, Q.; Zhang, N.; Xue, C.; Leung, A. W.; Zhang, H.; Tang, Q.; Xu, C.; Photodiagn. Photodyn. Ther. 2016, 15, 133.

24. Zhou, X.; Lin, X.; Xiong, Y.; Jiang, L.; Li, W.; Li, J.; Wu, L.; Int. Immunopharmacol. 2016, 34, 129.

25. Kim, Y. M.; Ha, Y. M.; Jin, Y. C.; Shi, L. Y.; Lee, Y. S.; Kim, H. J.; Seo, H. G.; Choi, J. S.; Kim, Y. S.; Kang, S. S.; Lee, J. H.; Chang, K. C.; Food Chem. Toxicol. 2009, 47, 2097.

26. Ikuta, A.; Nakamura, T.; Urabe, H.; Phytochemistry 1998, 48, 285.

27. Ikuta, A.; Urabe, H.; Nakamura, T.; J. Nat. Prod. 1998, 61, 1012.
28. Ikuta, A.; Nakamura, T.; Planta Med. 1995, 61, 581

29. Wang, M.; Ji, T. F.; Yang, J. B.; Su, Y. L.; Chin. Med. Mat. 2009, 32, 208.

30. Sun, C. L.; Li, J.; Wang, D. J.; Yu, J. Q.; Wang, X.; Wang, L. Q.; RSC Adv. 2015, 5, 75831 .

31. Zhu, H.; Wang, D. J.; Wen, L.; Yu, J. Q.; Geng, Y. L.; Zhao, H. Q.; Zhao, R. X.; Wang, X.; RSC Adv. 2016, 6, 83343.

32. Wang, X.; Geng, Y. L.; Li, F. W.; Jiang, J. H.; J. Sep. Sci. 2007, 30, 3214.

33. Wang, X.; Geng, Y. L.; Li, F. W.; Gao, Q. S.; Shi, X. G.; J. Chromatogr. A 2006, 1103, 166.

34. Sun, C. L.; Liu, F.; Sun, J.; Li, J.; Wang, X.; J. Chromatogr. A 2016 , 1427, 96.

35. Luo, Y.; Lai, Y.; Xue, Q.; Chin. Med. Mat. 2004, 27, 647.

36. Kim, E. K.; Jeong, E. K.; Han, S. B.; Jung, J. H.; Hong, J.; J. Korean Chem. Soc. 2011, 32, 3597.

37. Kim, H. R.; Min, H. Y.; Jeong, Y. H.; Lee, S. K.; Lee, N. S.; Seo, E. K.; Arch. Pharm. Res. 2005, 28, 1224.

38. Wafo, P.; Nyasse, B.; Fontaine, C.; Phytochemistry 1999, 50, 279. 